\title{
On Investigations of the Optical Absorption Coefficient of Gold and Germanium Implanted Silicon with the Use of the Non- destructive Contactless Photo Thermal Infrared Radiometry
}

\author{
Ł. CHROBAK ${ }^{1,2}$ and M. MALIŃSKI ${ }^{1}$ \\ 1.-Faculty of Electronics and Computer Science, Koszalin University of Technology, \\ 2 Śniadeckich St., 75-453 Koszalin, Poland. 2.—e-mail: lukasz.chrobak@tu.koszalin.pl
}

In this paper results of investigations of $\mathrm{Au}^{2+}$ and $\mathrm{Ge}^{+}$ion-implanted silicon samples with the use of the nondestructive frequency and the space domain photo thermal infrared radiometry (PTR) method are presented. Frequency amplitude characteristics and spatial amplitude distributions of the PTR signal for the implanted silicon samples were measured and analyzed. Measurements have been performed for several wavelengths of the exciting light. The dependence of the amplitude of the PTR signal on the optical and recombination parameters of the implanted layers has been analyzed experimentally and theoretically and discussed. The objective of this work is to present the possibilities of investigations of the influence of the high energy and high dose implantation process into silicon on the optical and recombination parameters of implanted silicon with the use of the frequency and spatial domain PTR method. Observed changes in the measured signal have been explained by simultaneous changes of values of the optical absorption coefficient and carriers lifetime of implanted layers.

Key words: Ion implanted silicon, nondestructive optical characterization, optical absorption coefficient, photo thermal infrared radiometry technique, implanted areas imaging

\section{INTRODUCTION}

Ion implantation causes changes in optical and recombination parameters of semiconductors and has a wide range of applications in a modern optoelectronics. For example, it enables making structures of a very large scale of integration., ${ }^{1,2}$ $\mathrm{Au}$ is one of the most important impurities in semiconductors, which allows controlling of the minority carriers lifetime, e.g., in fast switching devices. ${ }^{3,4}$ Implantation of $\mathrm{Au}$ ions allows obtaining strictly predictable structures. Its importance in designing of the functional silicon nanostructures has been described in paper. ${ }^{5}$ Gold ion implantation also can be used in a production of embedded Si

(Received February 21, 2019; accepted May 29, 2019; published online June 11, 2019) nanocrystals. ${ }^{6} \mathrm{Si}_{1-x} \mathrm{Ge}_{x}$ mixed crystals are used to improve the parameters of both CMOS and heterojunction bipolar transistors. To synthesize $\mathrm{Si}_{1-x} \mathrm{Ge}_{x}$ mixes crystals $\mathrm{Ge}^{+}$ion implantation is used. ${ }^{7,8}$ This implanation creates, however, both interstitial-type and vacancy-type defects in silicon. ${ }^{9}$ At present $\mathrm{Si}_{1-x} \mathrm{Ge}_{x}$ mixed crystals have been applied in the modern technology of electronic devices. ${ }^{10}$ The issue of oxidation of silicon structures implanted with germanium ions is presented in paper. ${ }^{11}$ In the last years nondestructive methods still have a wide range of applications in investigations of different types of materials. ${ }^{12}$ In this work we report results of investigations of $\mathrm{Au}^{2+}$ and $\mathrm{Ge}^{+}$ion-implanted silicon with the Photo Thermal Infrared Radiometry (PTR) method. ${ }^{13}$ This method is used for investigations of semiconductor materials like other photoacoustic (PA), ${ }^{14-20}$ photopyroelectric ${ }^{21-23}$ and Modulated Free Carriers Absorption (MFCA) ${ }^{24-28}$ 
methods. The PTR method has a wide range of different applications in investigations of many types of materials. One of the first and the most important ones is its application for investigations of so called transport properties of Si wafers. ${ }^{29}$ The PTR method was also used for investigations of implanted Si samples. Results of investigations of B implanted Si samples are presented in. ${ }^{30}$ Results of the PTR investigations of silicon implanted with $\mathrm{P}$ are presented in. ${ }^{31,32}$

Determination of the thermal diffusivity of different metals, such as: stainless steel, nickel, titanium, tungsten, molybdenum, zinc, and iron has been described in. ${ }^{33}$ Investigations of the thermal interface conductance and the mechanical adhesion strength in $\mathrm{Cu}$-coated glassy carbon was reported in. ${ }^{34}$ The heat transport in copper-carbon flat model systems was studied by the frequency-dependent photothermal radiometry and was described in. ${ }^{35}$ The PTR method was used for monitoring of amorfization of the implanted layers in silicon. ${ }^{36,37}$ The results of investigations of thin films with the use of the infrared radiometry have been presented in papers. ${ }^{38,39}$ The possibility of determination of thermal parameters of silicon and silicon-germanium crystals has been analyzed and described in. ${ }^{40}$ The PTR method also turned out to be a good tool for the thickness control of coatings. ${ }^{41}$ The photothermal radiometry can be used in the pulsed or periodic mode. ${ }^{42}$ In this paper the applications of the PTR method in the frequency and spatial modes have been presented.

\section{EXPERIMENTAL SET-UP AND A THEORETI- CAL BACKGROUND}

The experimental set-up for the frequency and spatial PTR measurements of semiconductor wafers has been presented in Fig. 1.

Silicon samples were illuminated with the laser light of diodes emitting at $808 \mathrm{~nm}, 660 \mathrm{~nm}, 520 \mathrm{~nm}$, and $480 \mathrm{~nm}$. The optical power of the lasers was 200 $\mathrm{mW}$. The intensity of the illuminating light was modulated by the LDC205C Benchtop LD Current Driver. As a result of the illumination periodical thermal and plasma waves were generated in the samples. The driver was controlled by a TTL signal of the SR 830 lock-in amplifier. The periodical component of the thermal radiation of the samples was detected by the infrared photovoltaic detector PVI-3TE-5 produced by the VIGO System S.A. The spectral sensitivity range of this photovoltaic detector is optimized for the $5.5 \mu \mathrm{m}$. This detector is equipped with a transimpedance amplifier for the frequency range $(10 \mathrm{~Hz}-1 \mathrm{MHz})$ and cooled with the thermoelectric system. The construction of a X-Y table is based on MLA-K modules. They are driven by step motors. All measurements were performed at room temperature and were computer controlled. The signal from a photovoltaic detector was acquired with a SR 830 Stanford Research phase

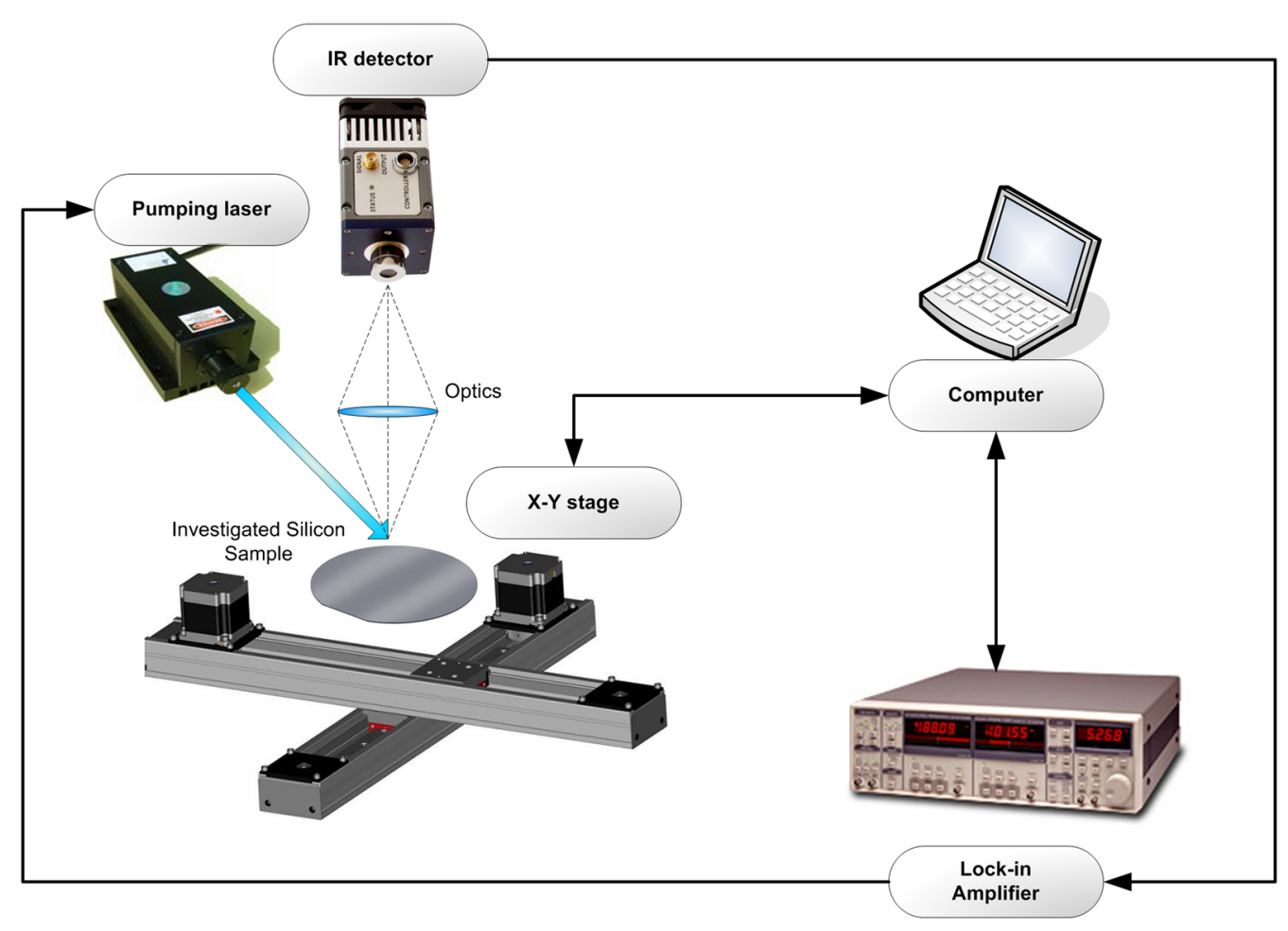

Fig. 1. Schematic diagram of the experimental set-up used in the PTR measurements. 


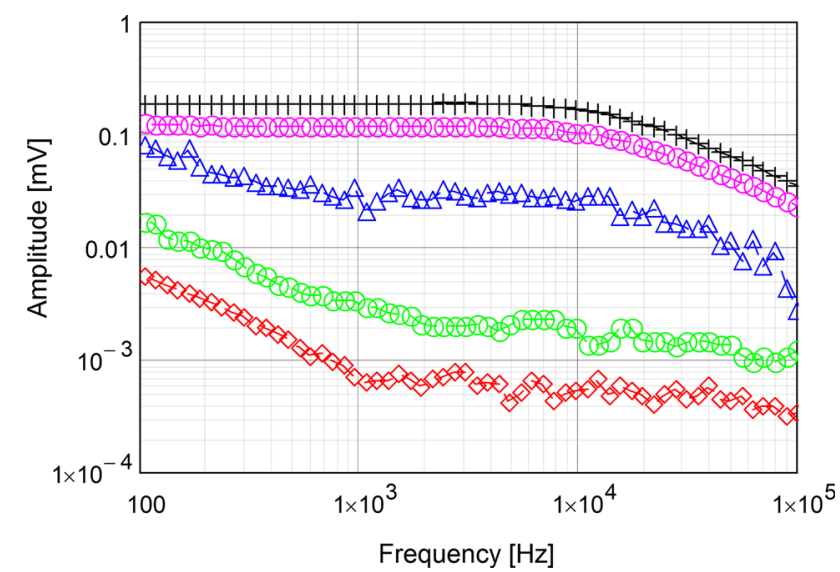

Fig. 2. Experimental amplitude PTR frequency characteristics of $\mathrm{Ge}^{+}$ion implanted $\mathrm{Si}$ samples measured at different wavelengths of the exciting laser light. Pluses-nonimplanted area of the sample $\lambda e x=808 \mathrm{~nm}$, diamonds-implanted area $\lambda e x=480 \mathrm{~nm}$, circlesimplanted area $\lambda e x=520 \mathrm{~nm}$, triangles-implanted area $\lambda \mathrm{ex}=660 \mathrm{~nm}$, circles-implanted area $\lambda \mathrm{ex}=808 \mathrm{~nm}$.

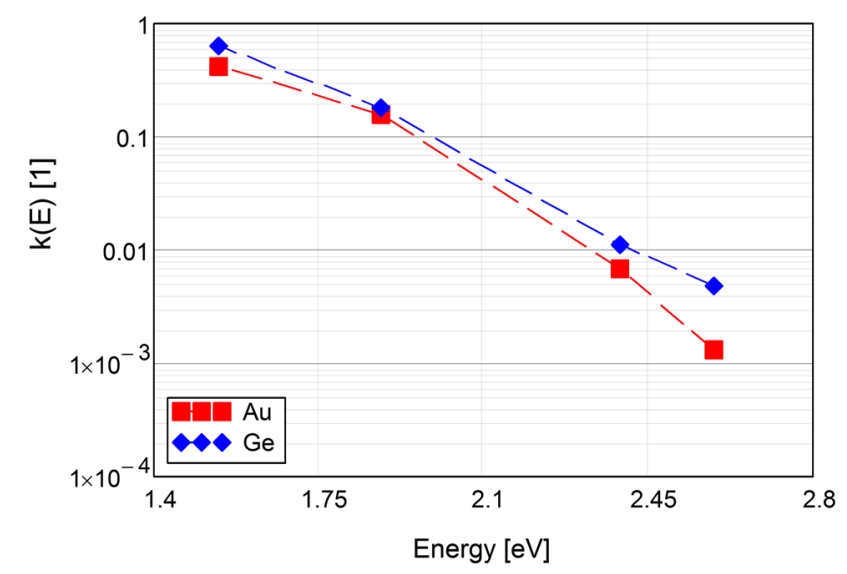

Fig. 3. Experimental amplitude dependence $k(E)$ of the PTR amplitude signals on the energy of absorbed photons measured for silicon samples implanted with $\mathrm{Au}^{2+}$ and $\mathrm{Ge}^{+}$ions. The frequency of modulation of the intensity of the exciting light $f=1 \mathrm{kHz}$.

sensitive amplifier which measured the amplitude and phase of the PTR signal.

The general expression for the PTR signal of a one-layer sample is expressed by formula (1) described in papers. ${ }^{4,44}$ It is a sum of the thermal and plasma wave components.

$$
S_{\mathrm{PTR}}(f)=a \cdot \int_{0}^{l} \Delta T(x, f) \cdot \partial x+b \cdot \int_{0}^{l} \Delta N(x, f) \cdot \partial x,
$$

where $x$ is a spatial coordinate, $f$-frequency of modulation, $\Delta T$-is a periodical component of the temperature, $\Delta N$-is a periodical component of the concentration of excess carriers, $l$-is the thickness of the sample.
The general expression for the PTR signal in a case of a two-layer sample is a sum of the PTR signals from the layer and from the substrate. The PTR signal can be then expressed by formula (2) and is described in detail in paper. ${ }^{45}$

$$
\begin{gathered}
S_{\mathrm{PTR}}=a_{i} \int_{0}^{d} \Delta T_{i}(x, f)+b_{i} \int_{0}^{d} \Delta N_{i}(x, f) \\
+a_{s} \int_{d}^{l} \Delta T_{s}(x, f)+b_{s} \int_{d}^{l} \Delta N_{s}(x, f),
\end{gathered}
$$

where $d$-is the thickness of the first, upper layer, $l$-is the thickness of the substrate.

For the frequencies of modulation bigger than $f=1 \mathrm{kHz}$ the plasma components dominate in the PTR signal and the PTR signal can be reduced to formula (3).

$$
S_{\mathrm{PTR}}=b_{i} \int_{0}^{d} \Delta N_{i}(x, f)+b_{s} \int_{d}^{l} \Delta N_{s}(x, f)
$$

In this paper formula (4) for the PTR signal of the implanted layer and the substrate was used. It is correct for the frequencies of modulation when the plasma wave component dominates in the PTR signal. In practice, for the investigated samples, it was for the frequencies above $f=1 \mathrm{kHz}$.

$$
\begin{aligned}
S_{\mathrm{PTR}}= & I_{0}\left[b \int_{0}^{d} \Delta N_{i}\left(x, f, \tau_{i}, D_{i}, \beta_{i}(E)\right)\right] \\
& +I_{0} e^{\left(-\beta_{i}(E) d\right)}\left[b \int_{d}^{l} \Delta N_{s}\left(x, f, \tau_{s}, D_{s}, \beta_{s}(E)\right)\right],
\end{aligned}
$$

where $f$ is the frequency of modulation of the intensity of the beam of light, $d$ is the thickness of the implanted layer, $l$-is the thickness of the substrate, $D_{i, s}$ is the diffusion coefficient of carriers, $\beta_{i, s}(E)$ is the optical absorption coefficient of the semiconductor for the energy of photons $E$ of the illuminating beam of light, $\tau_{i, s}$ is the lifetime of excess carriers. Symbols $i$ and $s$ denote the implanted layer and the substrate respectively.

\section{EXPERIMENTAL RESULTS}

$P$-type silicon wafers (111) grown by the Czohralski method were investigated. A dopant concentration in the investigated samples was about $10^{15}$ $\mathrm{cm}^{-3}$. Resistivity of the samples was $10 \Omega \mathrm{cm}$. Parameters of the implantation with $\mathrm{Au}^{2+}$ and $\mathrm{Ge}^{+}$ ions: energy of ions $200 \mathrm{keV}$ and $100 \mathrm{keV}$ respectively, a dose of implantation was $10^{14} \mathrm{~cm}^{-2}$. For the implantation a focused ion beam (FIB) machine 

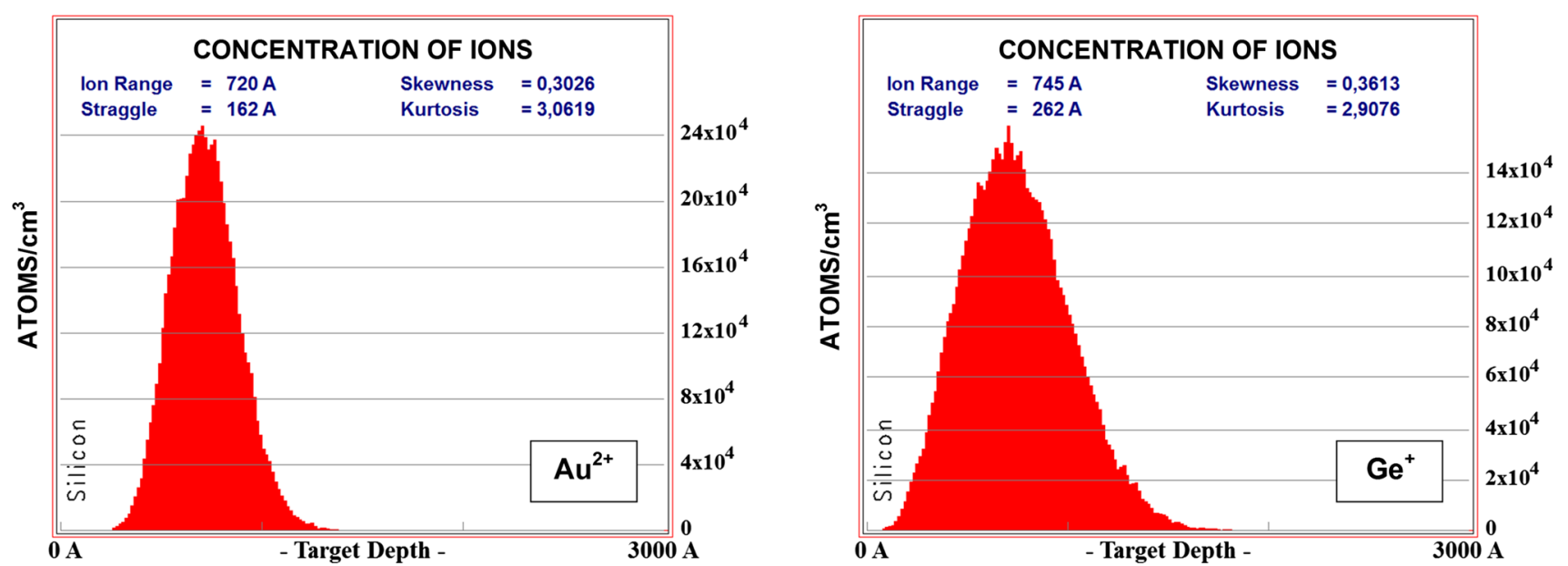

Fig. 4. Concentration of $\mathrm{Au}^{2+}$ and $\mathrm{Ge}^{+}$ions in silicon computed in the TRIM software. The thickness of the $\mathrm{Au}^{2+}$ implanted layer is $d=1440 \mathrm{~A}$. The thickness of $\mathrm{Ge}^{+}$implanted layer is $d=1490 \mathrm{~A}$.

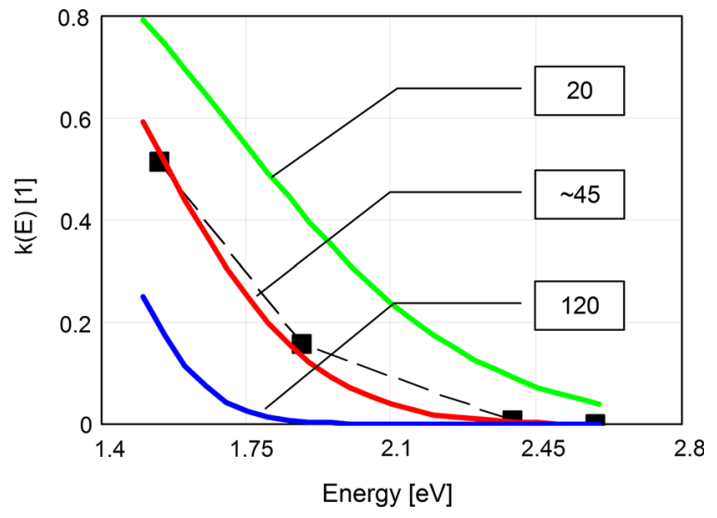

Fig. 5. Theoretical and experimental dependences of the $k(E)$ function on the energy of photons for the $\mathrm{Au}^{2+}$ implanted silicon layer. Squares are experimental $k(E)$ results. Solid lines are theoretical characteristics computed for different values of $n$. The best fitting of the theoretical characteristics to experimental data for the $\mathrm{Au}^{2+}$ implanted silicon layer was obtained for the value of the parameter $n=45.49 \pm 6.20$.

EIKO-100 under high-vacuum conditions of $10^{-7}$ mBar was used. Dimensions of the implanted area were $2 \mathrm{~mm} \times 2 \mathrm{~mm}$. Dimensions of the silicon substrate were $5 \mathrm{~mm} \times 5 \mathrm{~mm} \times 0.375 \mathrm{~mm}$.

The experimental amplitude PTR frequency characteristics at different wavelengths of the excitation light, obtained in the measurements of the investigated $\mathrm{Ge}^{+}$ion implanted samples are presented in Fig. 2.

The dependence $k(E)$, which is analyzed in this paper, is defined as the ratio of the amplitude of the PTR signal when the implanted region of the sample is illuminated to the amplitude of the PTR signal when the not implanted region of the silicon sample is illuminated. The frequency of modulation is above $1 \mathrm{kHz}$ and below $10 \mathrm{kHz}$, where the plasma contribution to the PTR signal dominates.

The experimental characteristics $k(E)$ were determined for each wavelength of the illuminating light for both ions and the frequency $f=1 \mathrm{kHz}$. They

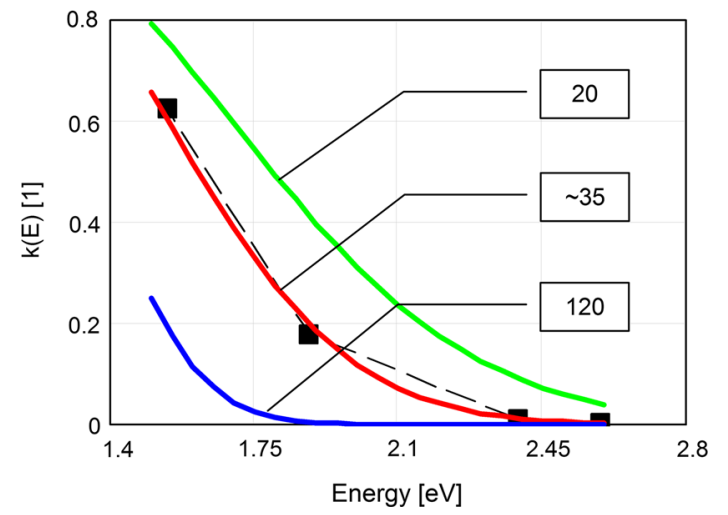

Fig. 6. Theoretical and experimental dependences of the $k(E)$ function on the energy of photons for $\mathrm{Ge}^{+}$implanted silicon layer. Squares are experimental $k(E)$ results. Solid lines are theoretical characteristics computed for different values of $n$. The best fitting of the theoretical characteristics to experimental data for the $\mathrm{Ge}^{+}$ implanted silicon layer was obtained for the value of the parameter $n=35.30 \pm 4.35$.

were determined from the frequency characteristics of the amplitude of the PTR signal.

The experimental characteristics $k(E)$, as a function of the energy of photons of the illuminating light, for investigated $\mathrm{Au}^{2+}$ and $\mathrm{Ge}^{+}$implanted silicon samples, are presented in Fig. 3.

To determine the average optical absorption coefficient spectrum $\beta_{\text {imp }}(E)$ of the implanted layer, its thickness must be known.

The TRIM application has been used for the estimation of the thickness of implanted layers. Results of these calculations have been presented in Fig. 4.

Let us assume that the average optical absorption coefficient spectrum of the implanted layer is $n$ times bigger than the optical absorption coefficient spectrum of the substrate. Assuming that the lifetime of carriers in the implanted layer is at least hundreds of time smaller than the lifetime of 


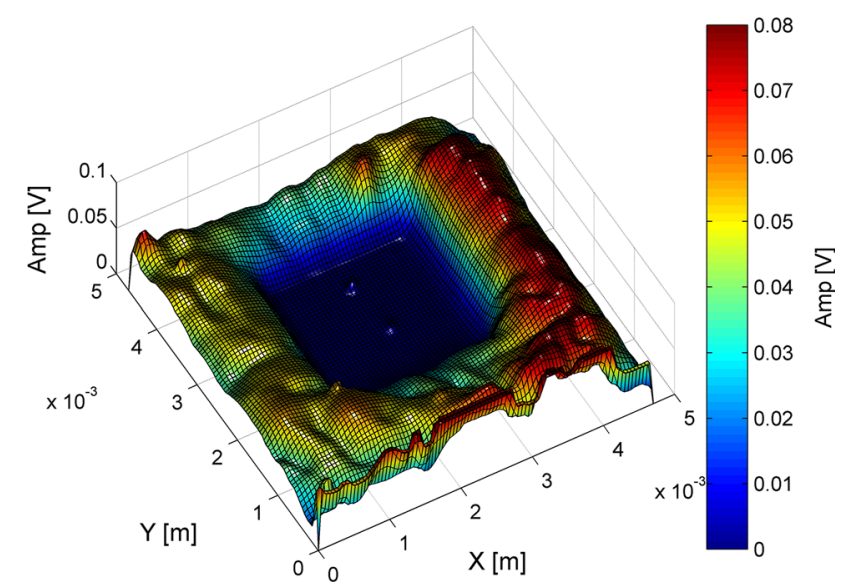

Fig. 7. The amplitude spatial distribution of the PTR signal for the example $\mathrm{Au}^{2+}$ implanted silicon sample for $\lambda_{\mathrm{ex}}=480 \mathrm{~nm}$ and $f=1 \mathrm{kHz}$.

carriers in a nonimplanted silicon, it can be proved that from the following formula (4) the dependence $k(E)$ can be expressed, in the first approximation, as:

$$
k(E)=\exp \left[-n \cdot \beta_{s}(E) \cdot d\right]
$$

where $E$ is the energy of photons, $d$ is a thickness of the implanted layer, $\beta_{s}(E)$ is the optical absorption coefficient spectrum of the substrate, $n$ is the number.

The characteristics of the $k(E)$ dependence on the energy of absorbed photons, both theoretical and experimental, for the $\mathrm{Au}^{2+}$ implanted silicon are presented in Fig. 5.

The characteristics of the $k(E)$ dependence on the energy of absorbed photons, both theoretical and experimental, for the $\mathrm{Ge}^{+}$implanted silicon are presented in Fig. 6.

The spatial distribution of the amplitude of the PTR signal obtained for the investigated $\mathrm{Au}^{2+}$ implanted silicon sample is presented in Fig. 7 .

The spatial distribution of the amplitude of the PTR signal obtained for the investigated $\mathrm{Ge}^{+}$ implanted silicon sample is presented in Fig. 8.

From the results presented in Figs. 7 and 8 a strong drop of the amplitudes of the PTR signal coming from the implanted areas is well visible for both $\mathrm{Au}^{2+}$ and $\mathrm{Ge}^{+}$.

Presented experimental characteristics of the implanted areas in silicon carry information about changes of the optical and recombination parameters of implanted regions.

\section{CONCLUSIONS}

In this paper results of investigations of the $\mathrm{Au}^{2+}$ and $\mathrm{Ge}^{+}$implanted silicon samples with the use of the frequency and space domain photo thermal infrared radiometry method have been presented. For the samples implanted with $\mathrm{Au}^{2+}$ and $\mathrm{Ge}^{+}$ions, of the energy $200 \mathrm{keV}$ and $100 \mathrm{keV}$, respectively, and a dose $10^{14} \mathrm{~cm}^{-2}$, a considerable drop of the

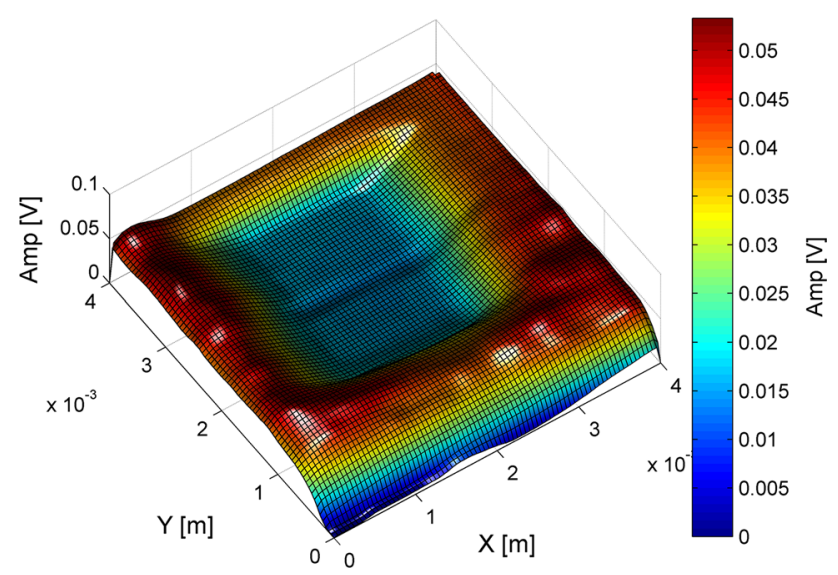

Fig. 8. The amplitude spatial distribution of the PTR signal for the example $\mathrm{Ge}^{+}$implanted silicon sample for $\lambda e x=808 \mathrm{~nm}$ and $f=1 \mathrm{kHz}$.

amplitude of the PTR signal was observed for the frequencies of modulation above $f=1 \mathrm{kHz}$ and below $10 \mathrm{kHz}$. This is the frequency region where the plasma component dominates in the PTR signal. This decrease, expressed by a characteristics $k(E)$, depended on the energy of photons of the exiting laser light. It decreased with the increase of the energy of photons and its character was very similar for investigated ions. The thickness of the implanted layers, computed in a TRIM program, was also similar (1440 A and 1490 A). Taking into account the thickness of the implanted layers and the values of their $k(E)$ functions, their average optical absorption coefficient spectra were computed. Comparison of the optical absorption coefficient spectrum of a non implanted silicon and the optical absorption coefficient spectra of $\mathrm{Au}^{2+}$ and $\mathrm{Ge}^{+}$implanted silicon layers leads to the conclusion that they increased about 45 and 35 times, respectively. The lifetime of carriers in the implanted areas decreased about $10^{4}$ times, under the assumption that the value of a diffusion coefficient of carriers of the implanted area is equal to $D_{i}=1.5$. $10^{-4} \mathrm{~cm}^{2} / \mathrm{s}$, respective to the lifetime of carriers in the silicon substrate. The presented results also prove that the PTR method, similar to the Modulated Free Carrier Absorption method (MFCA), is very attractive from the point of view of the possibility of a visualization of the silicon after the implantation process. The spatial contrast of the PTR amplitude signal depends on the experimental parameters such as the wavelength of the illuminating light and the frequency of its intensity modulation. It can reach the maximum value close to $100 \%$ for the wavelengths of the exciting laser light $\lambda \mathrm{ex}=480 \mathrm{~nm}$ and the frequency of modulation higher than $f=1 \mathrm{kHz}$. It is worth emphasizing that such a huge decrease of the amplitude of the PTR signal from the implanted areas can be explained only when the strong increase of the optical absorption coefficient and the strong decrease of the lifetime of carriers in the implanted areas are 
considered simultaneously. Changes of these parameters are connected with the amorphization of implanted silicon and are the consequence of creation of structural defects, in a crystal lattice of silicon, being the result of a high energy and high dose implantation. It also turned out that because the image contrast in the amplitude spatial distribution of the PTR signal can reach, depending on the experimental parameters values, $100 \%$ then the PTR method is a perfect tool for the visualization of the implanted areas in silicon. For comparison, the optical image contrast measured for the investigated samples reached the value $10 \%$. It was the result of the change of the optical reflection coefficient of implanted layers respective to the non implanted regions of silicon.

\section{ACKNOWLEDGMENTS}

We thank Dr. Nadezhda Kukharchyk for preparation of the silicon implanted samples.

\section{OPEN ACCESS}

This article is distributed under the terms of the Creative Commons Attribution 4.0 International License (http://creativecommons.org/licenses/by/4.0/), which permits unrestricted use, distribution, and reproduction in any medium, provided you give appropriate credit to the original author(s) and the source, provide a link to the Creative Commons license, and indicate if changes were made.

\section{REFERENCES}

1. A.G. Lewis, R.A. Martin, T.-Y. Huang, J.Y. Chen, and M. Koyanagi, IEEE Trans. Electron. Dev. ED-34, 2156 (1987).

2. N.W. Cheung, C.L. Liang, B.K. Liew, R.H. Mutikainen, and H. Wong, Nucl. Instrum. Methods B 37-38, 941 (1989).

3. J. Wong-Leung, J.S. Williams, and E. Nygren, Nucl. Instrum. Methods B 106, 424 (1995).

4. S. Coffa, L. Calcagno, G. Ferla, and S.U. Campisano, J. Appl. Phys. 68, 1601 (1990).

5. V. Lavrentiev, J. Vacik, V. Vorlicek, and V. Vosecek, Phys. Status Solidi B 247, 2022 (2010).

6. G. Sahu, R. Kumar, and D.P. Mahapatra, Silicon 6, 65 (2016).

7. M. Voelskow, I. Stoimenos, L. Rebohle, and W. Skorupa, Phys. Status Solidi C 8, 960 (2011).

8. K. Gao, S. Prucnal, A. Mücklich, W. Skorupa, and S. Zhou, Acta Phys. Pol. A 123, 858 (2013).

9. R. Kögler, A. Peeva, A. Mücklich, F. Eichhorn, and W. Skorupa, Appl. Phys. Lett. 88, 101918 (2006).

10. M.L. Lee and E.A. Fitzgerald, J. Appl. Phys. 97, 011101 (2005).

11. S.N. Dedyulin and L.V. Goncharova, Nucl. Instrum. Methods B 272, 334 (2012).

12. D. Balageas, X. Maldague, D. Burleigh, V.P. Vavilov, B. Oswald-Tranta, J.-M. Roche, C. Pradere, and G.M. Carlomagno, J. Nondestruct. Eval. 35, 18 (2016).

13. P.-E. Nordal and S.O. Kanstad, Phys. Scr. 20, 659 (1979).
14. M. Lukić, Ž. Ćojbašić, M.D. Rabasović, D.D. Markushev, and D.M. Todorović, Int. J. Thermophys. 38, 165 (2017).

15. D.M. Todorovic, M.D. Rabasovic, D.D. Markushev, V. Jovic, and K.T. Radulovic, Int. J. Thermophys. 38, 40 (2017).

16. A. Zegadi, M.A. Slifkin, M. Djamin, R.D. Tomlinson, and H. Neumann, Solid State Commun. 83, 587 (1992).

17. M. Maliński, Ł. Chrobak, and L. Bychto, Solid State Commun. 150, 424 (2010).

18. Ł. Chrobak, M. Malinski, and J. Zakrzewski, Thermochim. Acta 606, 84 (2015).

19. Ł. Chrobak, M. Maliński, and J. Zakrzewski, Thermochim. Acta 641, 79 (2016).

20. H. Benamrani, F.Z. Satour, A. Zegadi, and A. Zouaoui, J. Lumin. 132, 305 (2012).

21. K. Strzałkowski, Mater. Chem. Phys. 163, 453 (2015).

22. D. Dadarlat, M. Streza, O. Onija, C. Prejmerean, L. SilaghiDumitrescu, N. Cobirzan, and K. Strzałkowski, J. Therm. Anal. Calorim. 119, 301 (2015).

23. K. Strzałkowski, J. Phys. D Appl. Phys. 49, 435106 (2016).

24. S.W. Glunz and W. Warta, J. Appl. Phys. 77, 3243 (1995).

25. S.W. Glunz, A.B. Sproul, W. Warta, and W. Wettling, $J$. Appl. Phys. 75, 1611 (1994).

26. F. Sanii, F.P. Giles, R.J. Schwartz, and J.L. Gray, Solid State Electron. 35, 311 (1992).

27. M. Malinski, L. Chrobak, W. Madej, and N. Kukharchyk, Int. J. Thermophys. 38, 110 (2017).

28. Ł. Chrobak and M. Maliński, Opt. Mater. 86, 484 (2018).

29. A. Salnick, A. Mandelis, and C. Jean, Appl. Phys. Lett. 69, 2522 (1996).

30. M.E. Rodriguez, A. Mandelis, F. Rabago, and L. Nicolaides, Anal. Sci. 17, 277 (2001).

31. A. Othonos, C. Christofides, and A. Mandelis, Appl. Phys. Lett. 69, 821 (1996).

32. A. Othonos, A. Salnic, A. Mandelis, and C. Christofides, Phys. Status Solidi A 161, R13 (1997).

33. S. Pham Tu Quoc, G. Cheymol, and A. Semerok, Rev. Sci. Instrum. 85, 054903 (2014).

34. J. Pelzl, P. Kijamnajsuk, M. Chirtoc, N. Horny, and C. Eisenmenger-Sittner, Int. J. Thermophys. 36, 2475 (2015).

35. P. Kijamnajsuk, J. Pelzl, M. Chirtoc, N. Horny, D. Schäfer, and C. Eisenmenger-Sittner, Int. J. Thermophys. 33, 2132 (2012).

36. M. Maliński, M. Pawlak, Ł. Chrobak, S. Pal, and A. Ludwig, Appl. Phys. A Mater. 118, 1009 (2015).

37. Ł. Chrobak, M. Maliński, and M. Pawlak, Infrared Phys. Technol. 67, 604 (2014)

38. F. Macedo, F. Vaz, L. Rebouta, P. Carvalho, A. Haj-Daoud, K.H. Junge, J. Pelzl, and B.K. Bein, Vacuum 82, 1457 (2008).

39. J. Borges, F. Macedo, F.M. Couto, M.S. Rodrigues, C. Lopes, P. Pedrosa, T. Polcar, L. Marques, and F. Vaz, Mater. Chem. Phys. 163, 569 (2015).

40. Ł. Chrobak and M. Maliński, Infrared Phys. Technol. 89, 46 (2018).

41. S. Chotikaprakhan, F. Vaz, R.T. Faria Jr, A.C. Fernandes, P. Kijamnajsuk, J. Gibkes, B.K. Bein, and F. Macedo, J. Phys: Conf. Ser. 214, 012081 (2010).

42. A. Kusiak, J. Martan, J.L. Battaglia, and R. Daniel, Thermochim. Acta 556, 1 (2013).

43. A. Salnick, A. Mandelis, H. Ruda, and C. Jean, J. Appl. Phys. 82, 1853 (1997).

44. A. Mandelis, Solid State Electron. 42, 1 (1998).

45. M. Nestoros, Y. Karmiotis, and C. Christofidesa, J. Appl. Phys. 82, 6220 (1997).

Publisher's Note Springer Nature remains neutral with regard to jurisdictional claims in published maps and institutional affiliations. 